\title{
Subject domain restriction and reference-tracking *
}

\author{
Andrew McKenzie \\ University of Massachusetts Amherst
}

\begin{abstract}
This paper addresses a question: How does reference-tracking work with non-referential items? Specifically, it explores switch-reference, which typically tracks subjects, in the endangered Kiowa language (of Oklahoma). In it, I propose that switch-reference does not track reference of subjects at all; instead, it tracks the domain restricting resource situation of the subject. This proposal explains a wide variety of switch-reference facts in Kiowa, and the paper brings to light new data that advances our understanding of this reference-tracking phenomenon, and perhaps others like it.
\end{abstract}

Keywords: domain restriction, switch-reference, situation semantics, Kiowa

\section{Introduction}

\subsection{Switch-reference}

Switch-reference (SR) is a reference-tracking phenomenon that canonically marks whether the subjects of two joined clauses are co-referent or disjoint (Jacobsen 1967). In the Kiowa language ${ }^{1}, \mathrm{SR}$ is found on coordinating conjunctions and on some subordinating conjunctions or postpositions (Watkins 1984, 1993). It has two possible values. When the subjects co-refer, same (SS) marking appears, as in (1a). When they are disjoint, different (DS) marking appears. In (1b), the person who sits down is not Yisaum. This effect is also demonstrated for subordinate clauses in (2), with the postposition translated as 'when'.

(1) Joined by coordinating conjunctions:

* I thank Christina Simmons, George \& Margie Tahbone, Melva Wermy, David Geimausaddle, Gus Palmer, Jr., as well as all the family and friends who extended their hospitality to me during my fieldwork. I thank my advisors and colleagues at UMass Amherst for their advice, patience, and enthusiasm. This work was supported by an NSF Doctoral Dissertation Improvement Grant. Àhô!

1 Kiowa is a severely endangered language of the Kiowa-Tanoan family, spoken in Oklahoma (U.S). Only a few dozen elders are totally fluent, though hundreds of 'younger' Kiowas speak at varying skill levels. All Kiowa data were collected in fieldwork conducted by the author, unless noted, and are presented first in the Parker McKenzie orthography, then in IPA (except for examples I did not elicit). Agreement is glossed [subject:object:dative]. Abbreviations and glossing conventions are standard. 
a. SS (same) marking:

Yísàum hébà gàu èm sấu.

jírsõm $\varnothing-$ hé:ijbà go Rẽm- só:

Y. $\quad[3 \mathrm{~s}]$ enter.PF and.SS [3s:REFL] sit down.PF

'Yisaum 1 came in and he 1 sat down.'

b. DS (different) marking:

Yísàum hếbà nàu èm sấu.

jíss̃̃m $\varnothing-$ hé:jbà nõ $\quad$ iẽm- só:

Y. $\quad[3 \mathrm{~s}]$ enter.PF and.DS [3s:REFL] sit_down.PF

'Yisaum 1 came in and he $\mathrm{H}_{* 1 / 2}$ sat down.'

(2) Joined by subordinating conjunctions or postpositions:

a. SS (same) marking:

$$
\begin{aligned}
& \text { Hébàchè èm sáu } \\
& {\left[\varnothing-\text { hé: }^{\mathrm{j}} \text { bà }=\text { tsẽ: }^{\mathrm{j}}\right] \quad \text { ?ẽm }- \text { só: }}
\end{aligned}
$$

[3s] enter.PF=when.SS [3s:RFL] sit down.PF

'[When she ${ }_{1}$ came in], she ${ }_{1 / * 2}$ sat down.'

b. DS (different) marking:

$\begin{array}{cll}\text { Hébàè } & \text { èm } & \text { sáu } \\ {\left[\varnothing-\text { hé: }^{\mathrm{j}} \text { bà }=\text { êe: }{ }^{\mathrm{j}}\right]} & \text { Pẽm- } & \text { só: }\end{array}$

$[3 \mathrm{~s}]$ enter.PF=when.DS [3s:RFL] sit down.PF

'When she 1 came in, she ${ }_{* 1 / 2}$ sat down.

\subsection{Main question}

A lot of research has explored how switch-reference works in different languages. ${ }^{2}$ Also, several theoretical analyses have attempted to formally model how switchreference works. ${ }^{3}$ However, these analyses omit exploration of non-referential subjects. Examples almost exclusively deal with strongly referential subjects like personal pronouns, demonstratives, and proper names (expletives are the usual

2 In addition to scores of descriptive articles and sections in countless reference grammars, typologies of switch-reference in Australia (Austin 1981), North America (Jacobsen 1983) and Papua New Guinea (Roberts 1997) have been published, along with the varied proceedings of a symposium on SR (Haiman \& Munro 1983).

3 Most influential have been Finer's (1984) GB approach and Stirling's (1993) functionalist DRT approach, supplemented by, among others, Broadwell (1997); Watanabe (2000); Déchaine \& Wiltschko (2002) and McKenzie (2007). 
exception). This should come as no surprise, for naturalistic dialogues tend to be about specific people and things, and elicitation of examples with definite DPs is relatively efficient. This paper seeks to fill that lacuna, by exploring how switchreference behaves with some of the non-referential types of subjects that semantic research has uncovered: existential indefinites, $w h$-words, and negative quantified DPs. How does a reference-tracking system work when there is nothing to track?

\section{Switch-reference without reference}

Switch-reference indicates identity or non-identity of two DPs. ${ }^{4}$ For that, it needs to have access to the referents' identity. When subjects lack a referent, we might expect SR to behave in one of two ways.

\section{Expected results of SR with non-referential subjects}

i. SR is impossible, and does not appear. (i.e., it presupposes reference)

ii. DS marking is obligatory — without reference, there surely is no co-reference.

Surprisingly, neither outcome occurs in Kiowa. SR behaves as if these nonreferential items are in fact referential. Even when one or both subjects is not anaphoric, when intuition tells us the subjects co-refer, SS marking appears, and when they are disjoint, DS marking appears. The rest of this section provides detailed evidence of this.

\subsection{Existential indefinites}

Existential indefinites are considered non-referential in that they are not anaphoric. Indeed, their most common use as subjects is to introduce referents into the discourse. A subject need not be anaphoric to be visible to SR. (3) describes an assault by an unknown assailant. Since the same person is the subject of both joined clauses, SS appears.

$$
\begin{aligned}
& \begin{array}{lllll}
\text { Hájél } & \underline{\text { é }} & \text { góp } & \text { gàu } & \text { èm kífáu } \\
\text { hátél } & \text { Pẽ- } & \text { góp } & \text { go } & \text { Pẽm-kípó: }
\end{array} \\
& \text { person.INDEF [3s:1s] hit.PF and.SS [3s] jump off.PF }
\end{aligned}
$$

4 A lot of attention in the 70's and 80's focused on 'inclusive' or 'overlapping' reference, in cases like We came in and I sat down. The work produced suggests that a theory based on strict identity is not the final word on the matter. However, the facts are hard to generalize about, since they vary from one language to another, and sometimes within a language. This paper is part of a larger project built on the need to find out what switch-reference tells us about reference before tackling what it tells us about co-reference. As it turns out, the analysis in this paper hints at an approach to the inclusion issue that may well be successful. 
'Someone hit me and ran off.'

Consultant's comment: "I didn't see who it was."

If we replace SS in (3) with DS, the second conjunct's subject must be definite, and cannot refer to the first conjunct's subject.

$\begin{array}{lllll}\text { Hájél } & \underline{e} & \text { góp nàu } & \text { èm kífáu } \\ \text { hátél } & \text { ?ẽ }- & \text { góp } & \text { nõ } & \text { Tẽm- kí:pó: } \\ \text { person.INDEF } & {[3 \mathrm{~s}: 1 \mathrm{~s}]} & \text { hit.PF and.DS } & {[3 \mathrm{~s}]} & \text { jump off.PF }\end{array}$

'Someone 1 hit me and (s)he $_{* 1 / 2}$ ran off.'

Comment: "Maybe they were waiting for someone to distract me [ by hitting me ]."

Example (5) is similar, but with a second existential indefinite subject. DS marking is required here, as we might expect: In English and other observed languages, two consecutive existential indefinites are generally disjoint.

Hájél
hátél

'Someone hit me and someone (else) left.'

SR seems to treat indefinites as if they referred. An indefinite subject in the first conjunct is not itself problematic. SR has access to subjects of the first and second conjuncts, as the simple tree in (6) shows, using referential subjects.
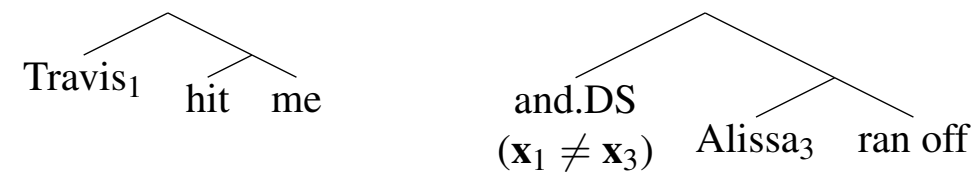

It is well observed that indefinites introduce a discourse referent; SR can access this from the first conjunct. But there is no way for it to also access the second conjunct's subject, since SR is outside the scope of the existentially quantified subject (7). What is SR tracking in the second conjunct?
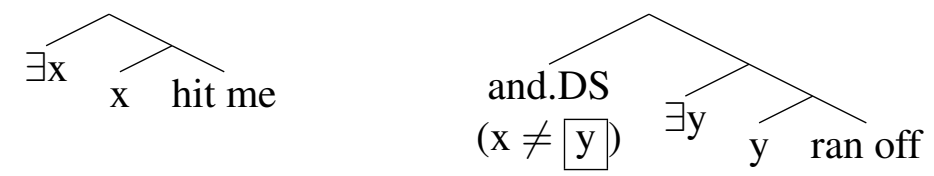

\subsection{Negative subjects}

Negative subjects are even more intriguing than existentials, because they do not introduce any referent at all. Nevertheless, SR treats them as if they do. So, we must ask how SR can judge co-reference of something that refers to no item. 
Subject domain restriction and reference-tracking

Kiowa lacks negative quantifiers; instead, indefinites are used in the scope of sentential negation. Still, SR indicates co-reference or disjointness. (8) describes a scenario where the dancers didn't sing, and (9) describes one where a dancer performed and nobody sang along.

$$
\begin{aligned}
& \text { Háun hájél [èm gúnmáuchè̀] èm dáujàugù }
\end{aligned}
$$

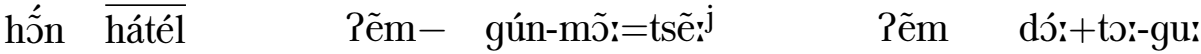

$$
\begin{aligned}
& \text { Not person.INDEF [3s.refl] dance-IMPF=when.SS [3s:refl] sing+act-NEG }
\end{aligned}
$$

'Nobody sang ${ }_{1}$ while they ${ }_{1}$ danced.'

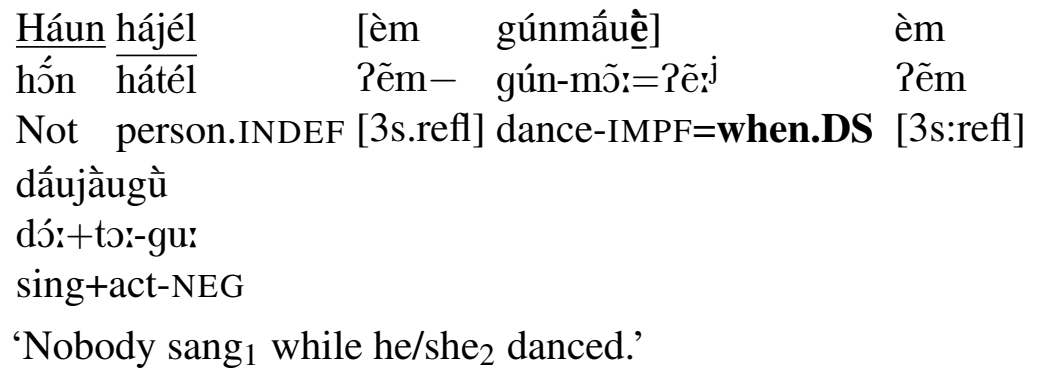

The DS marking indicates that the embedded subject is disjoint from nobody.

\subsection{Wh-subjects}

Wh-words are likewise not referential. They refer to sets of entities, but SR deals with them with no problems, as the SS (10) and DS (11) examples show.

\begin{tabular}{|c|c|}
\hline$\frac{\text { Hâjêl }}{\text { hồtềv1 }}$ & 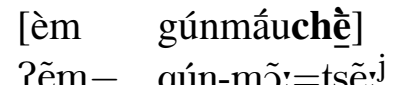 \\
\hline
\end{tabular}

person.WHQ [3s.refl] dance-IMPF=when.SS [3s:refl] sing+act(IMPF)

'Who 1 sang while they ${ }_{1}$ danced?'

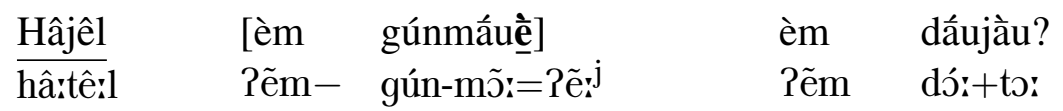

person.WHQ [3s.refl] dance-IMPF=when.DS [3s:refl] sing+act(IMPF)

'Who 1 sang while he/she 2 danced?'

\subsection{Bound variable subjects}

In the examples presented with negative and $w h$-subjects, the subjects bind a variable in the embedded SS-marked clause. The simplified tree in (12) shows this with negative subjects. When this binding occurs, SS is obligatory, even though it is comparing the 'reference' of two bound variables. 


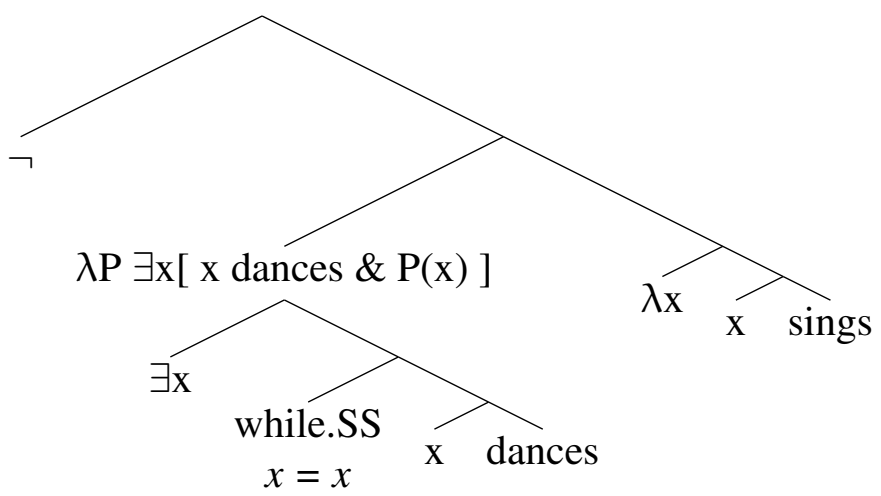

\subsection{Summary}

To summarize, switch-reference works with non-referential subjects as if they were referential. Sometimes, it deals with variables outside the scope of the existential operator. Other times, it deals with bound variables, though inside the scope of the operator. Assuming that reference tracking is still taking place, we are left with the question: what is SR tracking in these cases?

\section{Tracking RS}

This section proposes a hypothesis to account for the facts laid out in the previous section. It is built on a possibilistic situation semantics, and relies on a referential situation argument inside the subject that switch-reference tracks. Section 4 will show that Kiowa facts confirm the predictions made by this hypothesis.

\subsection{Hypothesis}

The hypothesis is this:

(13) Hypothesis: Switch-reference tracks the resource situation of subject DPs.

Instead of tracking the referent of these subjects, SR tracks the reference of the resource situation that restricts their meaning. Note that the hypothesis is not restricted to non-referential subjects. As we will see, resource situations are not restricted to non-referential subjects, so we can maximally strengthen the hypothesis beyond the non-referential, and test accordingly. Before detailing the mechanism behind this, let us turn a moment to the nature of resource situations.

I adopt a possibilistic situation semantics based on Kratzer 1989, 2007, which holds that situations are parts of worlds. Situations are represented in the semantics and syntax by pronouns, which can be bound or free. Situations are found at the 
sentence level (the 'topic situation') and inside DPs, as resource situations. A resource situation (RS) restricts the domain of a semantic operator to some part of the world. ${ }^{5}$ I adopt Schwarz's (2009) claim that situation variables are an argument of the operator, not the predicate. The quantified-over entity must be part of this situation.

For instance, the sentence Everyone is happy does not refer to everyone in the entire world; it is restricted to everyone in some part of the world (the room the speaker's in, for instance). The sentence can be re-represented as Everyone (in s) is happy, where $s$ is some anaphoric situation. Turning back to indefinites, we can express the quantifier some with a resource situation as follows:

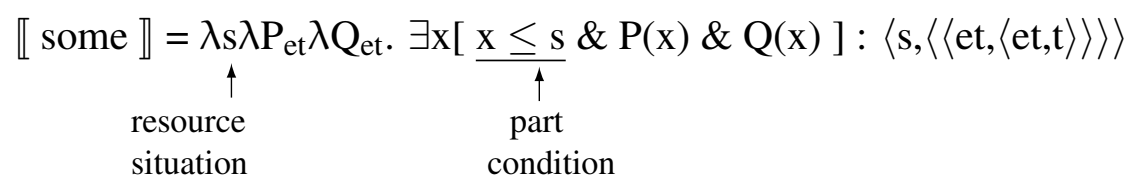

\subsection{SR tracks resource situations}

In (5), repeated in English as (14), the second subject's referent is not accessible to SR, since it is bound by an operator beneath it. However, its resource situation provides a referential object for SR to track. What DS marking indicates is that a person in some situation hit me, and a person in some other situation ran off. The difference in situation is enough to lead to an interpretation equivalent to indicating actual disjointness. The only requirement is for $\mathrm{s}_{3}$ to be anaphoric to some situation in the common ground; that is the case.

(14) Someone hit me and.DS someone ran off

(15) Someone in $s_{2}$ hit me and.DS someone in $s_{3}$ ran off
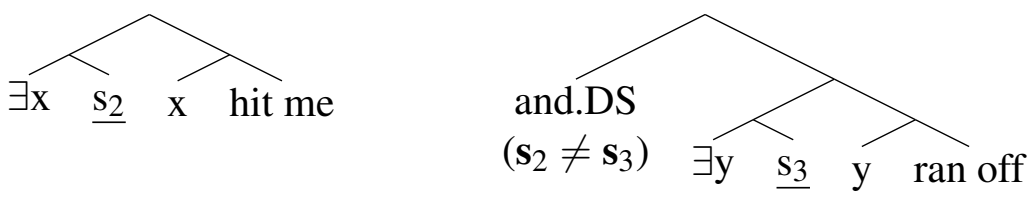

\section{Empirical results}

The hypothesis straightforwardly provides a referential object for switch-reference to track, so that in these cases, the referentiality of the subject itself is not at issue.

5 This version of situation semantics differs from Barwise \& Perry (1983)'s original proposal, but forms the basis of von Fintel 1994; Cooper 1996; Stanley \& Szabó 2000; Percus 2000; Kratzer 2004, among others. 
It also makes three strong predictions about the behavior of switch-reference with subjects, especially non-referential ones.

Three predictions of the hypothesis:

i. If the subjects of two clauses joined by SR derive their co-reference through their resource situation, SS marking is obligatory.

ii. If the subjects of two clauses joined by SR derive their disjointness through their resource situation, DS marking is obligatory.

iii. In other cases, SS or DS marking can appear.

The rest of this section demonstrates that these predictions hold.

\subsection{Prediction 1: Obligatory SS marking}

Under the hypothesis, if the two subjects' co-reference is derived by their resource situation, SR must appear as SS marking. We can test this using cases that have independently been demonstrated to involve co-reference via resource situations.

\subsubsection{SR and Donkey anaphora}

One well-examined case is donkey anaphora. A donkey-sentence requires SS marking when the subjects apparently co-refer.

$$
\begin{aligned}
& \text { Qậhì chêe dóchẹè àn gưgù }
\end{aligned}
$$

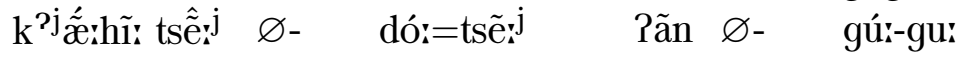

$$
\begin{aligned}
& \text { man horse [3s:3s] hold=when.SS HAB [3s:3s] hit-IMPF }
\end{aligned}
$$

In a situation semantics, resource situations can help determine co-reference. The indefinite in the embedded clause in (16) has a resource situation that is bound by an adverbial quantifier (in this case, the generic [GEN]). The 'donkey pronoun' in the main clause is not bound directly by the variable of the indefinite. Instead, its resource situation is bound by the adverbial quantifier (Berman 1987; Heim 1990). ${ }^{6}$ This binding derives the co-reference between $a$ man and he, and elegantly accounts for quantificational variability. It does this because the donkey pronoun is in fact a definite determiner with a co-variant resource situation.

We can thus paraphrase (16) as (17a); its meaning is expressed in (17b).

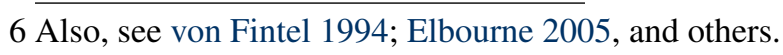


(17) a. Usually, if there is a situation exemplifying a man having a horse, there is also a situation exemplifying the man in that situation beating the horse in that situation.

b. $\lambda$ s. GEN $\underline{s^{\prime}}\left[\mathrm{s}^{\prime} \leq \mathrm{s} \& \exists \mathrm{x} \operatorname{man}(\mathrm{x})\left(\underline{\mathrm{s}^{\prime}}\right) \& \exists \mathrm{y} \operatorname{horse}(\mathrm{y})\left(\mathrm{s}^{\prime}\right) \&(\right.$ have $)(\mathrm{y})(\mathrm{x})\left(\mathrm{s}^{\prime}\right)$ $\left.\rightarrow \exists \mathrm{s}^{\prime \prime}\left[\mathrm{s}^{\prime} \leq \mathrm{s} " \leq \mathrm{s} \& \operatorname{beat}(\mathrm{y})\left(\mathrm{\iota x} . \operatorname{man}(\mathrm{x})\left(\underline{\mathrm{s}^{\prime}}\right)\right)\left(\mathrm{s}^{\prime \prime}\right)\right]\right]$

The identity of the subjects' resource situations derives their co-reference, and SS marking is required.

This account also explains switch-reference with impersonal subjects bound under an adverbial quantifier. Neither subject in (18) refers to anyone in particular (as indicated by default plural agreement), but SS marking indicates that whoever the subject is in the embedded clause is also the subjects in the main clause.

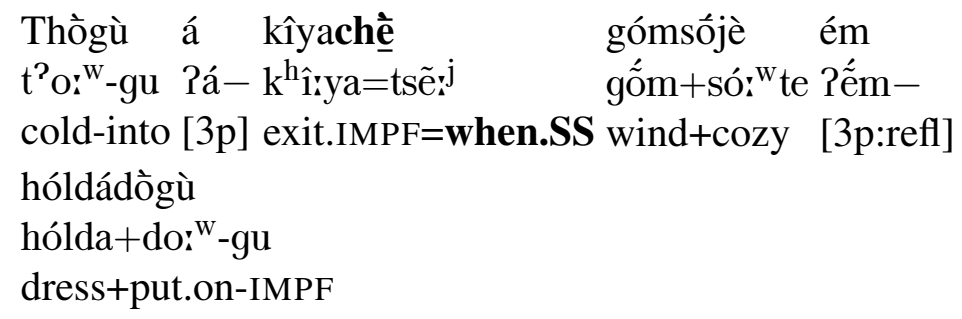

'When going out into the cold, one should dress warmly'

(Watkins, p.c.)

\subsubsection{Definite descriptions}

While the cases involving quantificational variability support the hypothesis, they are not as strong as cases of unexpected SR marking. These cases become readily apparent when we turn our attention away from indefinites. Resource situations are also used with definite determiners to preserve Russellian uniqueness. The iota operator selects an object in a domain and ascribes it a certain property only if it is the unique object in that domain to bear that property. The resource situation restricts the domain so that the uniqueness holds. For example, the expression the dog does not select the unique dog in the world, for there is no such dog. Instead, it selects the unique dog in some situation. The denotations of the definite determiner, and the dog, are adapted from Schwarz 2009:

$$
\begin{aligned}
& \llbracket \text { the } \rrbracket=\lambda s \lambda P_{\text {et. }} \text { เx. } \mathrm{x} \leq \mathrm{s} \& \mathrm{P}(\mathrm{x}):\langle\mathrm{s},\langle\text { et }, \mathrm{e}\rangle\rangle \\
& \llbracket \text { the } \operatorname{dog} \rrbracket=\text { เx. } \mathrm{x} \leq \mathrm{s} \& \operatorname{dog}(\mathrm{x})
\end{aligned}
$$

This account of definites leads to the donkey account provided above, and leads us to predict that if two conjoined sentences' subjects share a resource situation, SS marking appears, even if the subjects are definite descriptions. 


\subsubsection{Definites sharing a RS}

For instance, (21) is felicitous when describing a powwow. SS marking appears even though there is no way that yáucáuiǵu 'the young women' and jógúdàu 'the young men' can co-refer. ${ }^{7}$ However, the full meaning of these DPs requires domain restriction by a situation. In this case, both groups are restricted by the powwow: It's the young men at the powwow that sang, and the young women at the powwow that danced. This restriction is reflected in the consultant's comment.

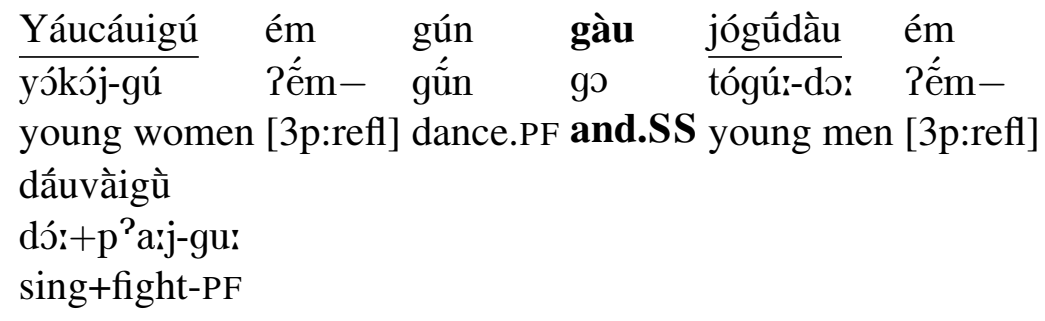

'The young women danced and the young men sang.'

Comment: "It was the ones that were there."

We can see in the tree below, that SS marking has access to the resource situations of each subject, and finding them identical, appears as SS marking.

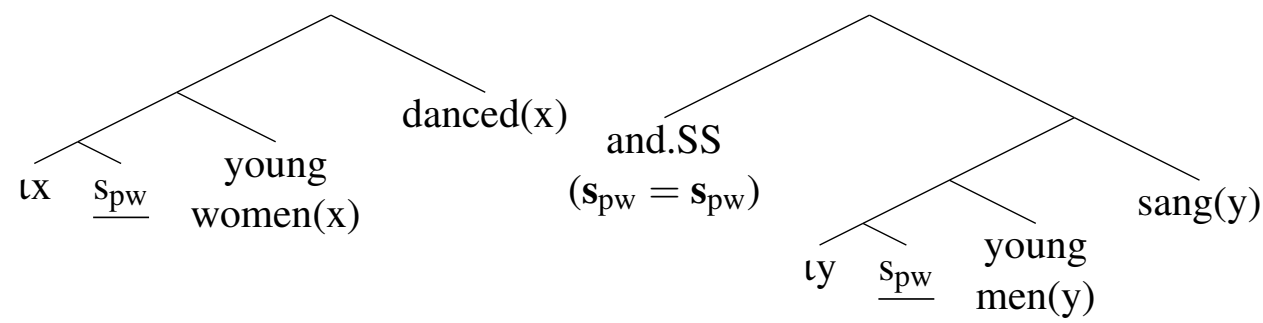

\subsection{Prediction 2: Obligatory DS marking}

Also following from the hypothesis is the condition that whenever the subjects must have different resource situations, only DS appears. Cooper (1996) provides a nice example where the subjects must have different resource situations. Here is a slight adaptation of that example.

Context: A university department of linguistics and philosophy are voting for a new head. There is one linguist candidate and one philosopher candidate.

(23) The linguists voted for the linguist, and the linguist won.

7 Kiowa does not have an overt definite determiner. However, consultants reliably understand uniqueness conditions when the context provides them. 
The uniqueness conditions of each definite subject forces them to have different resource situations. The second subject, the linguist, is the unique linguist in some situation, $s^{\prime}$. If the first subject were restricted by the same situation, it would select the unique group of linguists in $s^{\prime}$, but $s^{\prime}$ only contains one linguist, precluding the felicitous use of the plural.

A similar example in Kiowa demonstrates that, as predicted, DS marking appears (24) and SS marking is infelicitous (25).

Context: You're at an intertribal dance where they're electing a princess. But all the Kiowas voted for the Kiowa candidate, and all the Comanches voted for the Comanche. Since there were more Kiowas present, the Kiowa won.

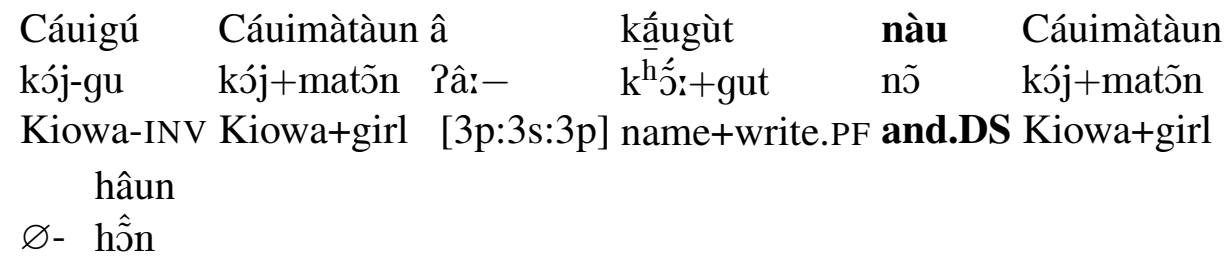

[3s] win.PF

'The Kiowas voted for the Kiowa, and the Kiowa won.'

\section{\#Cáuigú Cáuimàtàun â káugùt gàu Cáuimàtàun hân}

\subsection{Prediction 3: Non-obligatory SR allows either}

(24) also leads us to the third prediction - when there is no restriction on coreference deriving from the resource situations, either SS or DS can occur, depending on the context. This subsection demonstrates that this prediction holds.

\subsubsection{Solves puzzling cases}

The hypothesis sheds light on some puzzling cases of SR reported in the Kiowa literature. Previous researchers have noted unexpected SS marking with quantified subjects. In (26), SS is used despite the disjointness of the subjects. ${ }^{8}$ Under the hypothesis, SS indicates that the two subjects share a resource situation. That is, the two quantifiers select some proportion of the same group of people. Lacking the context behind this example, we can only surmise what those groups might have been; we might also imagine contexts that would lead to DS marking.

8 The second subject is a subset of the first, but this type of 'inclusive' co-reference normally triggers DS marking in Kiowa. 
Étjè tọchép hágá á càulè gàu fấ á many flood sometime [3p:3s] cross-IMPF.HSY and.SS some [3p] óbàhìhèl submerge+die.PF-HSY

'Many were once crossing a flood and some drowned.' (Watkins 1984: 159)

A more robust case is (27), because we do have the context: A group of hunters who are tracking down turkey. The first subject, they, is a definite description (the people in some situation $s_{1}$ ), and the second subject selects one individual out of $s_{1}$.

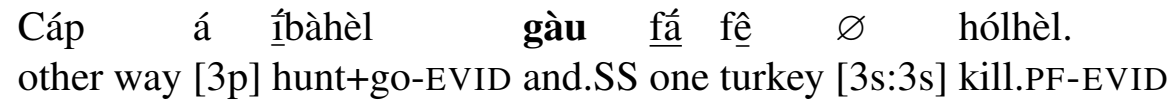

'They went on hunting in the other direction and one of them killed a turkey.' (Harbour 2007: 204)

\subsubsection{Partitives}

Providing an explanation for the unexpected SR marking in (26) and (27) lends support to the hypothesis, but is not ideal, because their naturalistic environments do not strictly rule out other possibilities. Targeted elicitation with contexts can be used to control for these possibilities. This subsection employs elicited data to explore the interaction of SR with partitive indefinite subjects.

Example (28) has two phonetically identical subjects, whose reference depends on their domain restricting resource situation. Each subject introduces a new group of people, and DS marking appears, as we would expect with a reference-tracking system.

$$
\begin{aligned}
& \text { Fấ gà dónmé nàu fấ áulhàuàui } \\
& \text { pá: } \quad g^{\mathrm{j}} \text { æ- dốnmế nõ } \quad \text { pá: } \quad \varnothing-\quad \text { Pól+ho: }+ \text { oj: } \\
& \text { some [3p] scarce and.DS some [3s:3pd] hair+metal+plentiful }
\end{aligned}
$$

'Some people don't have much (money) and some are rich.'

However, under the hypothesis, the two subjects must have different resource situations. What those situations are or should be is not immediately evident, because this sentence was elicited for simple translation, without a lead-in context. The goal was to elicit 'simple' conjoined sentences with expected SR markings. Having done that, I then asked for an acceptability judgments of (29), which is identical except for SR marking.

$$
\begin{aligned}
& \text { Fấ gà dónmé gàu fấ á aulhàuàui } \\
& \text { pá: } \quad g^{\mathrm{j}} \text { æ- dốnmẽ́ go } \quad \text { pá: } \varnothing-\quad \text { ?ól+ho: }+ \text { j: } \\
& \text { some [3p] scarce and.SS some [3s:3pd] hair+money+plentiful }
\end{aligned}
$$


Subject domain restriction and reference-tracking

'Some don't have much (money) and some have a lot of money.'

Under the hypothesis, the two subjects in (29) must have the same resource situation - they are different subsets of a salient group. There was no lead-in context to force such an interpretation, but one speaker's ensuing comments revealed sensitivity to a distinction between (28) and (29), along with insight about that distinction which the hypothesis predicts. In (28), the speaker reports talking about contrasting rich people and poor people. In (29), though, the speaker is just saying the way things are; they are talking about people in general.

\subsubsection{Forcing SS marking}

The hypothesis is further supported by elicitations with a lead-in context. For instance, in (30), the speaker is asked to translate from English within the realm of a recently introduced context.

Context: You are showing your friend around town, and you point to a wealthy rancher.

$$
\begin{aligned}
& \text { Úidè qậhì chêegàu áu âui, }
\end{aligned}
$$

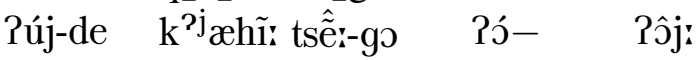

$$
\begin{aligned}
& \text { that-BAS man horse-INV }[\varnothing: 3 \mathrm{i}: 3 \mathrm{~s}] \text { plentiful } \\
& \text { 'That man has a lot of horses...' }
\end{aligned}
$$

Immediately after this, a follow-up was elicited; despite the subjects being disjoint, SS marking is not only allowed; it is the only felicitous response.
a. fầ á sáui gàu fầ á sáuibé
pá: Pá-sój go pá: Pá-sójbé
some [3p] fast and.SS some [3p] slow
'some of them are fast, some of them are slow'
b. \#fấ á sáui nàu fâ á sáuibé

This result is predicted by the hypothesis: The subjects in (31a) are different parts of the same situation, either the man's horses, or simply the set of horses introduced in (30). SR tracks the two resource situations, finds them identical, and SS marking appears, as this simplified tree demonstrates (I assume shorses to be the resource situation in question.)

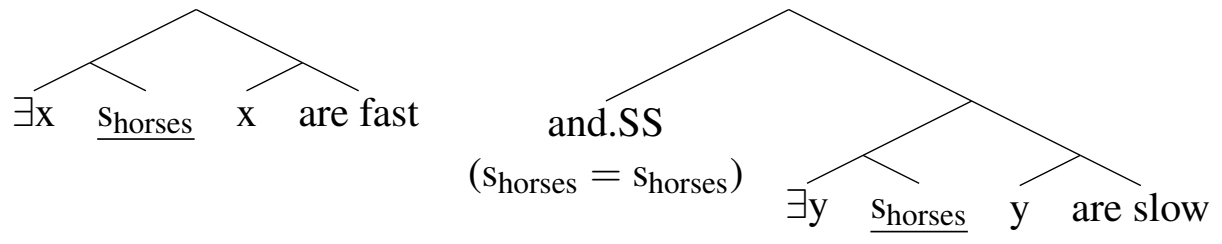


DS is infelicitous because the context forces (31b) to be elicited with respect to a certain previously introduced situation. DS marking would indicate that you are talking about some of the horses brought up in (30), and some other horses.

\subsection{Summary}

This section has outlined three successful predictions of the hypothesis proposed. Elicited evidence based on independent findings in the situation semantic literature shows that SR behaves in predictable ways with respect to indefinite subjects, and any other subjects whose reference depends on an operator restricted by a situation argument. The following section will explore similar effects with highly referential subjects.

\section{Extending the hypothesis}

Most of the attested cases of SR track referential subjects. To account for cases of SR tracking non-referential subjects, this paper proposes that SR tracks the domain restricting situation argument of the operator. This suggests that there are in fact two SRs: one SR that tracks situations, and another that tracks entities. This solution is unsatisfactory on theoretical grounds (it is inelegant) and on empirical grounds; no language splits SR into a situation tracking one and an entity tracking one. So, are we faced with dealing with two SRs? Or can we reduce these to a single SR?

\subsection{Referential subjects}

If we adopt Elbourne's (2005) finding that proper names and (3rd-person) pronouns are definite descriptions (33), we can conclude that all subjects have a resource situation argument. Therefore, we can safely hypothesize that switch-reference always tracks the subject's resource situation. ${ }^{9}$
a. $\llbracket$ Alissa $\rrbracket=$ tx. $\mathrm{x} \leq \mathrm{s} \& \operatorname{Alissa}(\mathrm{x})$
b. $\llbracket$ she $\rrbracket=$ เx. $x \leq \mathrm{s} \&$ female $(\mathrm{x})$

\subsection{Non-canonical SR}

One consequence of extending the hypothesis to all subjects is that we can now expect resource situation co-reference to trigger unexpected values of SR with highly referential subjects. The term non-canonical switch-reference describes

9 As mentioned before, I adopt the structure proposed by Schwarz (2009) where the resource situation is introduced by the operator, not the predicate. 
these cases, and they have been studied in a variety of languages (Dahlstrom 1982; Stirling 1993; McKenzie 2007: i.a) ${ }^{10}$ Watkins (1993) first describes non-canonical SR in Kiowa. In (34), the subjects refer to two different people, but SS marking appears.

$$
\begin{aligned}
& \text { Kathryn gà gút gàu Estheràl gà gút. } \\
& \text { K. } \quad g^{j} æ-\text { gú? go } \quad \text { E.=al } g^{j} æ-\quad \text { gú? } \\
& \text { K. } \quad[3 \mathrm{~s}: 3 p] \text { write.PF and.SS E. }=\text { too }[3 \mathrm{~s}: 3 p] \text { write.PF }
\end{aligned}
$$

'Kathryn wrote a letter and Esther wrote one too.'

(Watkins, 1993)

Watkins claims that event continuity or event identity is the source of SS marking; these actions are part of the same event. Indeed, McKenzie (2007) argues that the two conjuncts share an Austinian topic situation. However, the current hypothesis works just as well, as we can see once we explore (34) in light of a context. Multiple consultants of mine independently offered the same context when asked to describe when (34) would be acceptable.

Context: Kathryn and Esther are writing as part of a campaign to write the governor on behalf of a prisoner. ${ }^{11}$

Assuming that this campaign is referred to by a situation ( $\left.\mathrm{s}_{\mathrm{camp}}\right)$, we can see that under the hypothesis, SS marking indicates that the resource situation of Kathryn and Esther is identical: $\mathrm{s}_{\mathrm{camp}}$. Thus, their names can be denoted as in (35) and paraphrased as in (36): ${ }^{12}$

a. $\llbracket$ Kathryn $\rrbracket=$ Ix. $\mathrm{x} \leq \mathrm{s}_{\text {camp }} \& \operatorname{Kathryn}(\mathrm{x})$

b. $\llbracket$ Esther $\rrbracket=$ เx. $\mathrm{x} \leq \mathrm{s}_{\text {camp }}$ \& Esther( $\left.\mathrm{x}\right)$

a. 'the unique entity in $s_{\text {camp }}$ named Kathryn'

b. 'the unique entity in $\mathrm{s}_{\mathrm{camp}}$ named Esther'

The apparent event identity that previous researchers noted is derived from the common occurrence of binding by the sentence's topic situation of the subject's resource situation.

\subsection{Canonical SR}

The hypothesis explains non-canonical cases quite handily. But generally, referential subjects behave normally with respect to SR. That is, SR seems to track the individual

10 Pittman (2005) uses the term in an unrelated sense.

11 American states are in charge of most criminal justice in the U.S. Governors, as the chief executive of states, have the power to pardon anyone convicted of a crime in their jurisdiction.

12 See Poesio 1993 for similar examples with definite descriptions. 
referent. For instance, (37) is a completely expected use of DS marking.

$$
\begin{aligned}
& \text { Kathryn gà gút nàu Estheràl gà gút. } \\
& \text { K. } g^{\mathrm{j}} \text { - gú? no } \quad \text { E.=al } g^{\mathrm{j}} \text { - gú? } \\
& \text { K. } \quad[3 s: 3 p] \text { write.PF and.DS E. }=\text { too }[3 s: 3 p] \text { write.PF }
\end{aligned}
$$

'Kathryn wrote a letter and Esther wrote one too.'

According to the hypothesis, DS marking indicates that the two subjects have disjoint resource situations. But what are they? I propose that they are co-extensive to the individuals themselves.

\subsection{Co-extensive resource situations}

Sometimes, a domain restricting situation co-extends to the individual or set of individuals being picked out by the quantifier or determiner. Thus, if Kathryn is a person, there is some 'Kathryn situation' ( $\mathrm{s}_{\text {Kathryn }}$ ), and so on, for all individuals. The paraphrase of the name Kathryn in (37) is 'the unique individual in $\mathrm{s}_{\text {Kathryn }}$ whose name is Kathryn' Since the 'Kathryn situation' differs from the 'Esther situation', DS marking appears. The fact that these descriptions end up selecting different people is irrelevant. The denotation of these subjects is in (38), while a tree sketch is in (39).

$$
\text { a. 【Kathryn } \rrbracket=\text { เx.Kathryn(x) \& } \mathrm{x} \leq \mathrm{S}_{\text {Kathryn }}
$$

b. $\llbracket$ Esther $\rrbracket=$ เx.Esther $(\mathrm{x}) \& \mathrm{x} \leq \mathrm{s}_{\text {Esther }}$

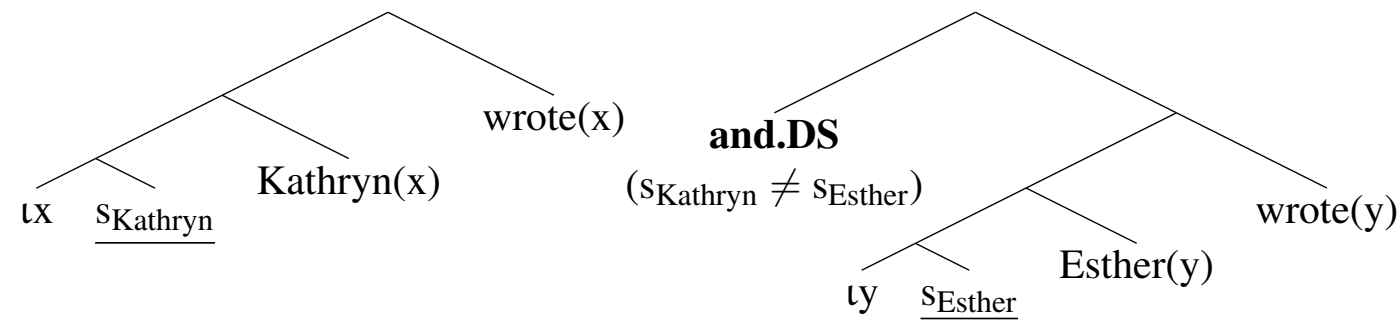

Under this account, what appears to be tracking a referent is in fact tracking of a co-extensive resource situation. Canonical SR appears so often because we generally refer to people we know by name using their co-extensive resource situation, which is the most informative. Exceptions occur when some other situation is more salient, and the individual's role in that situation is a more important or reliable identification method than simply using a co-extensive situation.

\subsection{Possessors as resource situations}

One final example that supports the hypothesis demonstrates the use of SR to track resource situations being used to link parts of individuals to the individuals 
themselves. It comes from a narrative by Parker McKenzie about an incident where some Kiowas were butchering a cow given them by nearby White settlers. As they got to work, the Whites began to crowd around them in trepidatious anticipation. Eventually, the Kiowas tired of the attention and decided to frighten the onlookers with a prank. In the example below, which takes place before the pranking begins, the first subject "White people" is the possessor of the second subject "eyes," but SS marking appears.

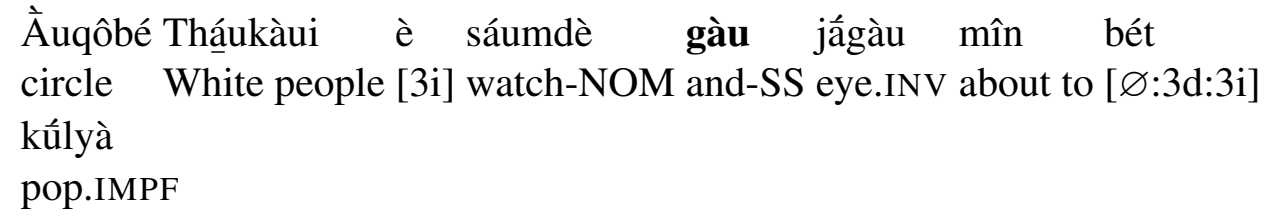

'The White people stood all around watching and their eyes were about to pop out.' (Parker McKenzie, ms.)

Clearly people and eyes do not co-refer. However, under the hypothesis presented here, all that matters is the resource situation. Each subject has the same resource situation, and we can surmise that it is the White people themselves ( $\mathrm{s}_{\mathrm{wp}}=$ the White people). Thus, the first subject's RS is co-extensive ('the White people in $\mathrm{s}_{\mathrm{wp}}$ '), and the second's is not ('the eyes in $\mathrm{s}_{\mathrm{wp}}$ ').

\subsection{Summary}

This section has demonstrated that extending the hypothesis to highly referential subjects is successful. It explains typical uses of SR, by positing that actual reference tracking of subjects is illusory. Instead, SR always tracks resource situations. Canonical SR occurs when those situations co-extend with the individual, while noncanonical SR occurs when the situation does not. Also, certain types of part-whole bridging, which have independently been linked to situations, trigger predictable effects in SR behavior.

\section{Conclusion}

This paper began with a question: How does switch-reference track the reference of subjects that do not refer? It found that switch-reference is able to track nonreferential subjects by tracking their resource situation. Under the assumption that all DPs have a resource situation, it leads to the conclusion that SR never tracks the reference of subjects at all; it only tracks their resource situations. This proposal explains several cases of unexpected SR by linking them to independently demonstrated roles of resource situations in natural language. In doing so, it proposes a new approach to exploring switch-reference and reference tracking systems in 
general. It also breaks empirical ground, examining cases of SR that had never been discussed before.

\section{References}

Austin, Peter. 1981. Switch-Reference in Australia. Language 57(2). 309-334. doi: $10.2307 / 413693$.

Barwise, Jon \& John Perry. 1983. Situations and attitudes. Stanford, CA: CSLI.

Berman, Stephen. 1987. Situation-Based Semantics for Adverbs of Quantification. In Juliette Blevins \& Anne Vainikka (eds.), UMOP 12, UMass Amherst: GLSA.

Broadwell, George Aaron. 1997. Binding Theory and Switch-reference. In Hans Bennis, Pierre Pica \& Johan Rooryck (eds.), Atomism and Binding, 31-49. Dordrecht: Foris Publications.

Cooper, Robin. 1996. The Role of Situations in Generalized Quantifiers. In Shalom Lappin (ed.), Handbook of contemporary semantic theory, Oxford: Blackwell.

Dahlstrom, Amy. 1982. A functional analysis of switch-reference in Lakhota. In Chicago Linguistics Society, vol. 18, .

Déchaine, Rose-Marie \& Martina Wiltschko. 2002. Decomposing pronouns. Linguistic Inquiry 33(1). 409-442. doi:10.1023/A:1014214222614.

Elbourne, Paul. 2005. Siutations and individuals. Cambridge, Massachusetts: MIT dissertation.

Finer, Daniel. 1984. The formal grammar of switch-reference. Amherst, Mass.: University of Massachusetts-Amherst dissertation.

von Fintel, Kai. 1994. Restrictions on quantifier domains. Amherst, Mass.: University of Massachusetts-Amherst dissertation.

Haiman, John \& Pamela Munro (eds.). 1983. Switch-reference and universal grammar. Amsterdam: John Benjamins.

Harbour, Daniel. 2007. Morphosemantic number: From Kiowa noun classes to UG number features. Dordrecht: Springer.

Heim, Irene. 1990. E-type pronouns and donkey anaphora. Linguistics and Philosophy 13(2). 137-177. doi:10.1007/BF00630732.

Jacobsen, William H., Jr. 1967. Switch-Reference in Hokan-Coahuiltecan. In Dell Hymes \& William Bittle (eds.), Studies in Southwestern Linguistics, 238-263. The Hague: Mouton.

Jacobsen, William H., Jr. 1983. Typological and Genetic Notes on Switch-Reference in North American Languages. In Switch-Reference and Universal Grammar, 151-183. Philadelphia: John Benjamins. 
Subject domain restriction and reference-tracking

Kratzer, Angelika. 1989. An investigation of lumps of thought. Linguistics and Philosophy 12(5). 607-653. doi:10.1007/BF00627775.

Kratzer, Angelika. 2004. Covert quantifier restrictions in natural languages. Talk given at Palazzo Feltrenelli, Gargnano, Italy.

Kratzer, Angelika. 2007. Situations in Natural Language Semantics. In Stanford Encyclopedia of Philosophy, Palo Alto, CA: CSLI.

McKenzie, Andrew. 2007. Non-canonical switch-reference and topic situations. Ms. University of Massachusetts Amherst.

Percus, Orin. 2000. Constraints on Some Other Variables in Syntax. Natural Language Semantics 8(3). 173-229. doi:10.1023/A:1011298526791.

Pittman, Christine M. 2005. Non-canonical Switch-reference in Inuktitut. In Claire Gurski (ed.), Proceedings of the CLA annual conference, .

Poesio, Massimo. 1993. A situation-theoretic formalization of definite description interpretation in plan elaboration dialogues. In Peter Aczel, David Israel, Yasuhiro Katagiri \& Stanley Peters (eds.), Situation Theory and its Applications, vol. 3, chap. 12, 339-374. Stanford: CSLI.

Roberts, John. 1997. Switch-Reference in Papua New Guinea. In Andrew Pauley (ed.), Papers in Papuan Linguistics 3, 101-241. Canberra, ACT, Australia: Australian National University.

Schwarz, Florian. 2009. Two types of definites in natural language: University of Massachusetts-Amherst dissertation.

Stanley, Jason \& Zoltán Gendler Szabó. 2000. On quantifier domain restriction. Mind and Language 15(2-3). 219-261. doi:10.1111/1468-0017.00130.

Stirling, Lesley. 1993. Switch-Reference and Discourse Representation. Cambridge, England: Cambridge University Press.

Watanabe, Akira. 2000. Feature Copying and Binding: Evidence from Complementizer Agreement and Switch-Reference. Syntax 3(3). 159-181. doi:10.1111/1467-9612.00031.

Watkins, Laurel. 1984. A Grammar of Kiowa. Lincoln, Nebraska: University of Nebraska Press.

Watkins, Laurel. 1993. The Discourse Function of Kiowa Switch-Reference. International Journal of American Linguistics 59(2). doi:10.1086/466193. 


\author{
Andrew McKenzie \\ Dept. of Linguistics \\ 226 South College \\ University of Massachusetts Amherst \\ 150 Hicks Way \\ Amherst, MA 01003 \\ armckenz@linguist.umass.edu
}

